\title{
CYTOPLASMIC INCLUSIONS AND NUCLEAR CHANGES IN CELLS INFECTED WITH INFLUENZA-B VIRUSES
}

\author{
Alicja Porebska*, H. G. Pereira and J. A. Armstrong \\ National Institute for Medical Research, Mill Hill, London \\ Plate XII
}

PRIMARY monkey kidney cultures have been shown to be particularly suitable for the propagation of influenza-B viruses (Mogabgab et al., 1955). Evidence of virus multiplication in this system is usually tested for by haemadsorption or by the observation of cytopathic effect. Examination of fixed and stained cultures reveals, in addition, the development of inclusions. These have been observed in different cell culture systems (Brandt, 1961; Berkaloff, Stussi and Colobert, 1962; Harwin, Joosting and Gear, 1966), but their study has not been pursued and little information is available regarding their nature or their relation to the process of virus multiplication.

In the course of routine identification of virus strains received for study at the World Influenza Centre a systematic search was conducted for inclusions produced by influenza viruses in primary monkey kidney cultures. Influenza-B viruses were regularly found to produce characteristic basophilic inclusions in the cytoplasm of infected cells. Some strains also produced marked alterations of intranuclear structure and staining properties. Some characteristics of these inclusions and nuclear changes are described in the present paper.

\section{MATERIALS AND METHODS}

Virus strains. Standard laboratory strains of influenza B (Lee, B/Johannesburg/33/58) and 18 recent isolates received for identification were propagated either in embryonated eggs by the allantoic route or in primary monkey kidney cultures. Infective allantoic or tissue culture fluids were preserved at $-70^{\circ} \mathrm{C}$.

Antisera. Influenza B/Lee antiserum was obtained from a ferret infected by intranasal inoculation and bled 2 wk later. Anti-V and anti-S guinea-pig sera were prepared according to the technique described by Lief and Henle (1959). Acute and convalescent sera from patients with virological diagnosis of influenza B were supplied by Dr Marguerite S. Pereira of the Virus Reference Laboratory, Colindale, London.

Monkey kidney cultures. Primary cultures of rhesus monkey kidneys, maintained in medium 199 (Morgan, Morton and Parker, 1950) without serum, were inoculated with appropriate virus dilutions and replicate tubes were examined at intervals for haemadsorption and cytological alterations.

Haemadsorption was tested by adding $0.1 \mathrm{ml}$ of a 0.5 per cent. suspension of guinea-pig erythrocytes which were allowed to settle on to the cell sheet for $15 \mathrm{~min}$. at $4^{\circ} \mathrm{C}$. Quantitative haemadsorption was estimated by the technique described by Finter (1964).

* Present address: Akademia Medyczna, Zaklad Mikrobiologii Lekarskiej, Krakow, Poland. Received 29 Feb. 1968; accepted 3 Apr. 1968.

J. MED. MICROBIOL.-VOL. 1 (1968) 
Cytology. For microscopical observations infected and control monolayers were obtained on coverslips placed in some of the tubes. Coverslips were removed at intervals up to 3 days after virus inoculation. Bouin's fixative was used prior to routine staining with haematoxylin and eosin. Monolayers fixed in ethanol were stained for nucleic acids by means of the acridine orange fluorescence technique (Armstrong and Hopper, 1959) or with methyl green and pyronin, or by the Feulgen technique. Others were stained for polysaccharides by the periodic acid-Schiff (PAS) technique.

Immunofluorescence. Monolayer cultures inoculated $24 \mathrm{hr}$ previously with strain Lee were rinsed in phosphate-buffered saline at $p \mathrm{H} 7.9$ (PBS), and fixed in absolute ethanol at room temperature. After rehydration they were again washed in PBS and treated for $30 \mathrm{~min}$. at room temperature with anti-S or anti-V guinea-pig serum; they were then rinsed several times in PBS, stained with fluorescein-labelled rabbit anti-guinea-pig- $\gamma$-globulin, washed and mounted in PBS. Controls consisted of virus-inoculated cells treated with normal guinea-pig serum before the labelled anti-guinea-pig- $\gamma$-globulin, and also of uninfected cells treated with influenza-B antisera followed by the labelled $\gamma$-globulin. The cultures were inspected by dark-field fluorescence microscopy, with long wave ultraviolet activation.

Electron microscopy. Tube cultures of monkey kidney cells, inoculated $48 \mathrm{hr}$ previously with $\mathrm{B} /$ Johannesburg/497/65 strain, were prepared for thin sectioning alongside uninfected controls. The cells were fixed for $1 \mathrm{hr}$ with a 1 per cent. phosphate-buffered $(p \mathrm{H} \mathrm{7.3)}$ solution of osmium tetroxide (Millonig, 1961); or for $15 \mathrm{~min}$. with 2.5 per cent. glutaraldehyde in $0.1 \mathrm{M}$ phosphate buffer $(\mathrm{pH} \mathrm{7.3)}$ followed by $1 \mathrm{hr}$ in Millonig's osmium tetroxide solution. They were dehydrated with ethanol and embedded in " Epikote" epoxy resin. Thin sections were stained with uranyl acetate andl ead citrate.

Virus neutralisation. Serial two-fold dilutions of sera inactivated for $30 \mathrm{~min}$. at $56^{\circ} \mathrm{C}$ were mixed with a constant virus dose previously estimated to induce a sufficient number of inclusions $24 \mathrm{hr}$ after inoculation. Cultures containing coverslips were inoculated with $1 \mathrm{ml}$ of serum-virus mixture in medium 199 and incubated for $24 \mathrm{hr}$ at $37^{\circ} \mathrm{C}$. Coverslips stained with haematoxylin and eosin were examined and the proportion of cells containing basophilic cytoplasmic inclusions was estimated from a total count of approximately 1000 cells per coverslip. Neutralisation end-points were taken as the serum dilutions estimated to reduce the number of cytoplasmic inclusions to 50 per cent. of the controls without serum.

We performed complement fixation tests in WHO Perspex plates as previously described (Pereira, Pereira and Law, 1964) using soluble antigen obtained from the chorio-allantoic membranes of eggs infected with influenza $B /$ Lee.

\section{RESULTS}

All the strains of influenza-B virus examined in this study invariably gave rise to the formation of conspicuous cytoplasmic inclusions when inoculated into monkey kidney cell cultures; obvious nuclear changes were produced however by only a proportion of the strains tested.

\section{Cytology}

In monolayers stained with haematoxylin and eosin, cytoplasmic inclusions appeared as well-defined, strongly basophilic bodies. In the early stages they consisted of small discrete granules, but these showed a marked tendency to coalesce, and at later stages formed an irregular mass of basophilic material practically surrounding the nucleus (figs. 1 and 2); occasionally this formed a dense cap adhering to the nucleus. The development of inclusions was generally accompanied by a marked reduction in the normal diffuse cytoplasmic basophilia. 
In cells stained with acridine orange and viewed by fluorescence microscopy with blue-violet activation, the inclusion bodies showed intense red fluorescence suggesting the presence of RNA. They also stained with pyronin, but were negative to the Feulgen and PAS techniques.

Nuclear changes, when present, occurred mostly in cells also showing the typical cytoplasmic inclusions. With haematoxylin and eosin, affected nuclei were purplish in colour, and mottled, due to aggregation of chromatin and accumulation of eosinophilic material inside the nucleus (fig. 2); later on the chromatin showed margination, and the eosinophilic material tended to occupy the central area around the nucleolus. A higher proportion of altered nuclei

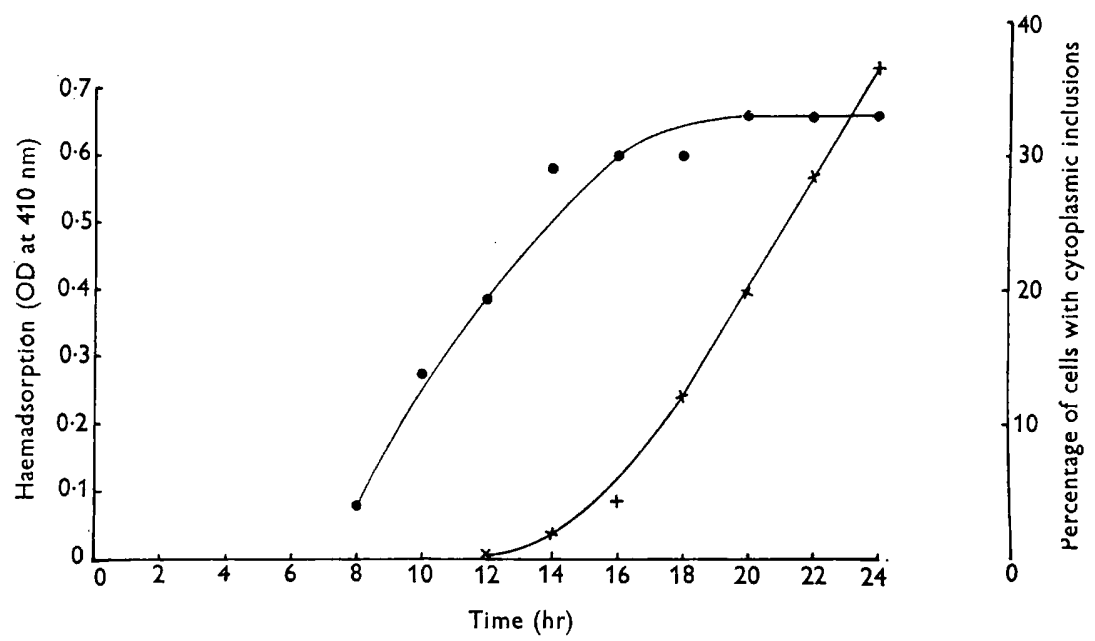

FIG. 3.-Development of haemadsorption (closed circles) and cytoplasmic inclusions (crosses) in primary monkey kidney cultures inoculated with influenza $B / L$ Lee virus at a multiplicity of approximately 1 EID50 per cell.

was revealed by acridine orange staining; material giving a diffuse red fluorescence of RNA type seemed to fill the whole nucleus, as described previously in bovine kidney cell cultures infected with some A strains of influenza virus (Niven et al., 1962).

\section{Quantitative aspects}

The proportion of cells showing cytoplasmic inclusions could be readily estimated in infected coverslip cultures stained with haematoxylin and eosin, and was found to vary according to size of virus inoculum and time of incubation. The kinetics of the appearance of cytoplasmic inclusions and of the development of haemadsorption in cultures inoculated with the Lee strain at a multiplicity of approximately 1 EID50 per cell is shown in fig. 3. Haemadsorption was first detected at $8 \mathrm{hr}$ and reached its maximum level at about $20 \mathrm{hr}$. Cytoplasmic inclusions were first seen at $12 \mathrm{hr}$ and showed a continuous increase in number up to $24 \mathrm{hr}$, beyond which it became increasingly difficult to estimate their numbers because of extensive degeneration and detachment of infected cells. Time of appearance of cytoplasmic inclusions varied inversely with size 
of virus inoculum, and at constant incubation times the proportion of cells with inclusions increased in direct proportion to virus dose. In cultures incubated for up to 4 days, inclusion formation was less sensitive than haemadsorption as an indicator of virus multiplication, but it is possible and indeed seems likely, that these two effects would reach comparable levels with longer incubation.

A specific relation between inclusion formation and virus multiplication was demonstrated by virus neutralisation tests performed with sera from a ferret experimentally infected with influenza $B /$ Lee and with paired sera from patients with clinically and virologically diagnosed influenza B (table).

TABLE

Virus neutralisation and complement-fixation titres of paired human sera and ferret antiserum to influenza $B$

\begin{tabular}{|c|c|c|c|c|}
\hline \multirow[b]{2}{*}{ Serum } & \multirow[b]{2}{*}{ Virus strain } & \multicolumn{2}{|c|}{ Virus neutralisation titre of serum by } & \multirow[b]{2}{*}{$\begin{array}{l}\text { Complement- } \\
\text { fixation } \\
\text { titre of serum }\end{array}$} \\
\hline & & $\begin{array}{l}50 \text { per cent. } \\
\text { inclusion- } \\
\text { inhibition test }\end{array}$ & $\begin{array}{l}50 \text { per cent. haem- } \\
\text { adsorption- } \\
\text { inhibition test }\end{array}$ & \\
\hline $\begin{array}{l}\text { 767-acute } \\
\text { 767-convalescent } \\
\text { 769-acute } \\
\text { 769-convalescent } \\
\text { 775-acute } \\
\text { 775-convalescent } \\
\text { Ferret antiserum }\end{array}$ & $\begin{array}{c}\text { B/England/7/66 } \\
\text { ", } \\
\text { ", } \\
\text { B/,̈ee }\end{array}$ & $\begin{array}{r}12 \\
100 \\
80 \\
620 \\
160 \\
15,000 \\
10,000\end{array}$ & $\begin{array}{r}<20 \\
40 \\
20 \\
320 \\
20 \\
1280 \\
5120\end{array}$ & $\begin{array}{r}<10 \\
320 \\
<10 \\
160 \\
<10 \\
160 \\
\ldots\end{array}$ \\
\hline
\end{tabular}

The figures represent reciprocals of serum dilution giving 50 per cent. virus neutralisation or complement fixation.

The fact that sera from human subjects naturally infected with influenza B showed significant rises in virus neutralisation titres demonstrable both by haemadsorption and by inclusion-inhibition tests in parallel with complement fixation is particularly indicative of a relation between inclusion formation and multiplication of influenza B.

\section{Immunofluorescence}

Many cells in the monolayers infected with strain Lee, and examined by the indirect fluorescent antibody technique with anti-S serum, showed strong intranuclear fluorescence (fig. 4), whereas fluorescence following the use of anti-V serum was localised predominantly at the cell surfaces (fig. 5). With neither type of serum was specific fluorescence localised in structures corresponding to the basophilic cytoplasmic inclusions, which were demonstrated in parallel cultures stained with haematoxylin and eosin.

Fine structure

In the cultures fixed for electron microscopy, $48 \mathrm{hr}$ after inoculation, a wide spectrum of cytopathic changes due to myxovirus infection was evident, 
Cytoplasmic INCLUSIONS IN INFLUENZA B

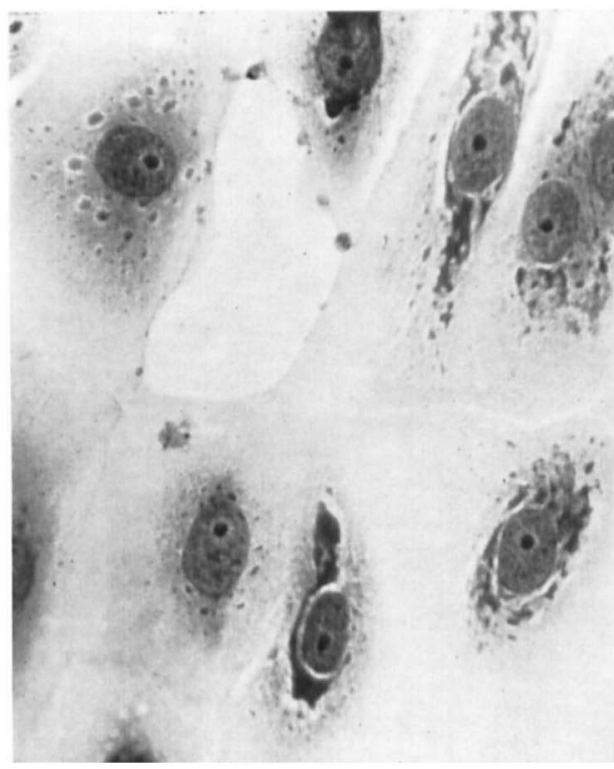

FIG. 1.-Primary monkey kidney cell monolayer showing different stages of cytoplasmic inclusions induced by influenza $\mathrm{B} /$ Lee. Haematoxylin and eosin. $\times 400$.

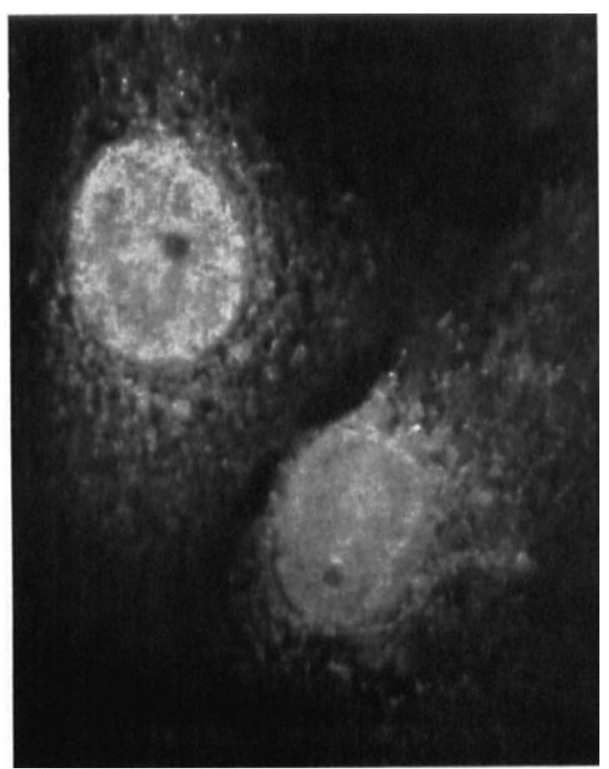

FIG. 4.-Primary monkey kidney cells infected with influenza B/Lee virus and treated with homologous anti-S guinea-pig serum, followed by fluorescein-labelled anti-guinea-pig- $\gamma-$ globulin. Material showing specific fluorescence is predominently intranuclear. Fluorescence photomicrograph. $\times 900$.

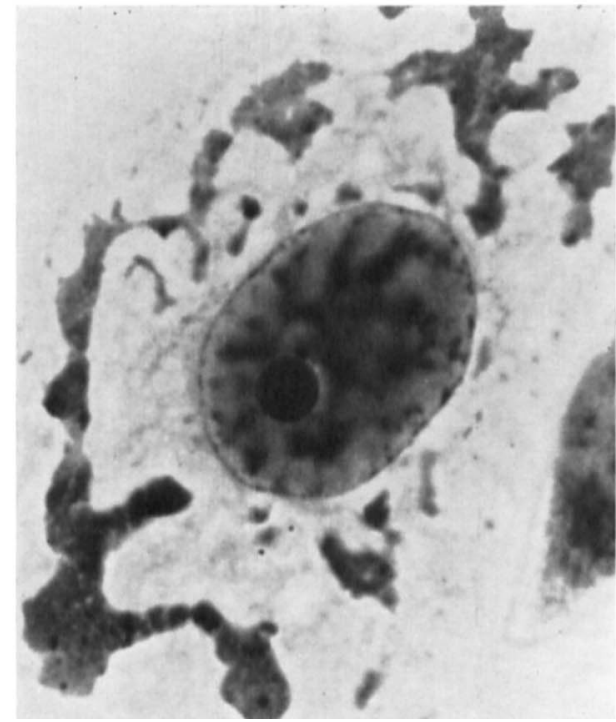

FIG. 2.-Well-developed basophilic cytoplasmic inclusions and nuclear alteration, induced by influenza $B /$ Lee in a primary monkey kidney cell. HE. $\times 1160$.

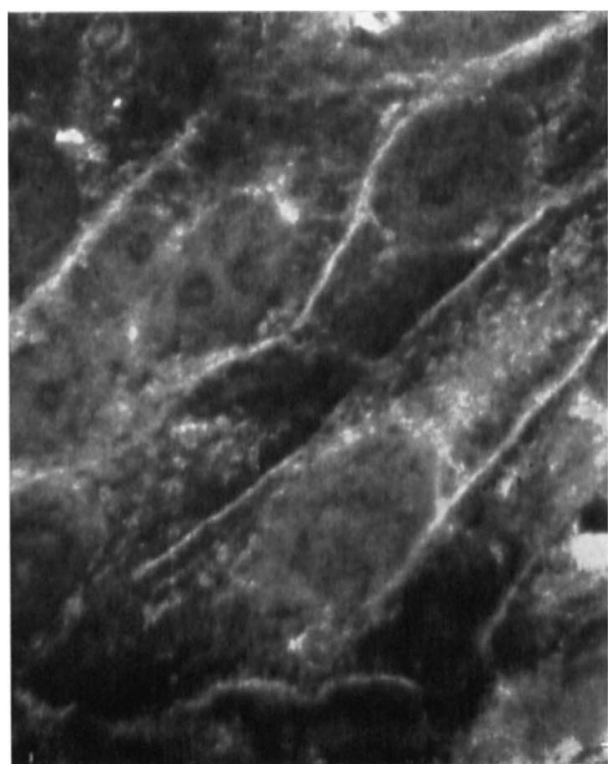

FIG. 5.-Monkey kidney cell monolayer infected with influenza B/Lee, and treated with homologous anti-V guinea-pig serum followed by fluorescein-labelled anti-guinea-pig- $\gamma$-globulin. Specific fluorescence is extranuclear, and largely intercellular in location. Fluorescence photomicrograph. $\times 720$. 
ranging from early to terminal stages in different cells; very few normal cells remained. Myxovirus particles occurred in profusion on the outer surfaces of some cells, many clearly budding from the cell membrane. Some virus was present also in large cytoplasmic vacuoles. The particles were spherical or rod-like; filamentous forms were not seen. The spheres measured about $90 \mathrm{~nm}$ in diameter; each had a fibrillar or granular core structure, a distinct limiting envelope and a diffuse outer coat in which radial spicules were sometimes discernible. The virus growth pattern appeared to be no different from that shown in earlier studies on A and B strains of human influenza virus (Morgan, Rose and Moore, 1956; Berkaloff et al., 1962; Niven et al., 1962; Berkaloff and Colobert, 1963). It was very noticeable that most of the cells showing active virus formation had minimal vacuolation or other obvious disturbance of normal cytoplasmic and nuclear fine structure. Frankly degenerate or damaged cells showed little or no sign of virus particle production.

Surprisingly, some difficulty was experienced at first in identifying cytoplasmic inclusions in the thin sections. It was noted, however, that large and welldefined aggregates of closely packed ribosome-like particles were a common feature of the perinuclear areas in many cells, and there can be little doubt that it is these that are seen as basophilic inclusions at the light microscope level. They were most evident in cells that appeared to be at advanced stages of infection, showing vacuolation and other features of cytoplasmic and nuclear degeneration, but little if any of active virus formation at the cell surface.

\section{Discussion}

It is remarkable that production of inclusions during infection with influenza$B$ viruses has received such scant attention hitherto. This is probably due, at least in part, to the fact that examination of fixed and stained cultures is not commonly performed in routine diagnostic work, and also that the typical basophilic inclusions are not produced in chick embryo cells, which until recently have been the type most often used for the study of these viruses. With increasing use of monkey kidney cells for the isolation of influenza $B$ it is worth calling attention to the occurrence of characteristic cytoplasmic inclusions, which can be helpful in the rapid distinction of influenza B from other haemadsorbing viruses isolated from patients with respiratory infections. In a limited search for the formation of influenza-B inclusions in HeLa cells, we have found that some virus strains are capable of inducing cytoplasmic inclusions with low efficiency. This is in line with observations by Berkaloff et al. (1962) who reported that a multiplicity of at least 10 ID50 per cell was necessary for the production of cytoplasmic inclusions by influenza $\mathrm{B} /$ Lee in KB cells. This is in marked contrast to our findings in primary monkey kidney cells, in which inclusions are produced regularly at much lower multiplicities.

The basophilic nature of influenza-B cytoplasmic inclusions makes them clearly distinguishable from the eosinophilic inclusions produced, for example, by the parainfluenza viruses. However, inclusions very similar to those produced by influenza-B strains have been described by Coackley and Pini (1965) 
in monolayers infected with the virus of Nairobi sheep disease. Also similar in morphology, though not in staining reaction, are the typical inclusions produced by reoviruses; the latter differ fundamentally from influenza-B inclusions in that they represent intracytoplasmic sites of viral synthesis and accumulated virus particles. A number of influenza A2-strains were examined for comparison and all of them failed to form cytoplasmic inclusions in primary monkey kidney cells. Niven et al. (1962) showed that some influenza-A strains in calf kidney cell cultures may cause changes in nuclear morphology and staining reaction similar to those observed here; both in Niven et al.'s study and in our own there was evidence from fluorescent antibody staining that the nuclear changes were related to the formation of viral S antigen. Formation of both nuclear and cytoplasmic inclusions apparently resembling those produced by influenza-B strains were reported recently by Ter Meulen and Love (1967) in HeLa cells infected with a PR 8-Mel recombinant virus; these authors' findings suggested that inclusion formation and production of infectious virus may be independent events.

The exact nature of the cytoplasmic inclusions described in the present paper is still uncertain, but it is clear that they are formed at late stages of infection and do not contain virus particles, or viral antigens in quantities that are detectable by immunofluorescence. They have a substantial RNA content, and their fine structure suggests that they may result from extensive aggregation of host cell ribosomes, due possibly to disturbance of metabolic processes which occurs at a late stage of the infection.

\section{SUMMARY}

Basophilic cytoplasmic inclusions, often accompanied by nuclear changes, develop regularly in primary monkey kidney cell cultures infected with influenza$B$ viruses. The inclusions stain positively for RNA, and electron microscopy shows them to contain large aggregates of ribosome-like particles. Inclusions form late in the infection, and it has not been possible to correlate them with the synthesis of virus-specific antigens. The capacity of influenza-B virus to give rise to inclusions is specifically neutralised by virus antibody. The inclusions seem to be a useful character for the distinction of influenza-B strains from other haemadsorbing viruses.

\section{REFERENCES}

Armstrong, J. A., AND Hopper, P. K. . 1959. Expl Cell Res., 16, 584.

Berkaloff, A., ANd Colobert, L. . . . 1963. J. Microscopie, 2, 433.

Berkaloff, A., Stussi, T., AND Colobert, 1962. Ibid., 1, 351.

L.

BRANDT, C. D. . . . . . . . . . 1961. Virology, 14, 1.

CoACKLEY, W., AND PinI, A. . . . . 1965. J. Path. Bact., 90, 672.

FINTER, N. B. . . . . . . . . . . 1964. Virology, 24, 589.

HaRwin, R. M., Joosting, A., AND Gear, 1966. Lancet, 1, 1218.

J. H. S.

Lief, Florence S., AND Henle. W. . 1959. Bull. Wld Hlth Org., 20, 411. 


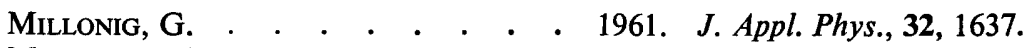

Mogabgab, W. J., Green, I. J., Dier- 1955. Proc. Soc. Exp. Biol. Med., 89, 654. Khising, O. C., ANd Phillips, I. A.

Morgan, C., Rose, H. M., AND Moore, 1956. J. Exp. Med., 104, 171.

D. $\mathrm{H}$.

Morgan, J. F., Morton, Helen J., And 1950. Proc. Soc. Exp. Biol. Med., 73, 1. PARKER, R. C.

Niven, Janet S. F., Armstrong, J. A., 1962. J. Path. Bact., 84, 1.

BALFour, Brigid M., Klemperer,

H. G., AND TyrRell, D. A. J.

Pereira, H. G., Pereira, Marguerite 1964. Bull. Wld Hlth Org., 31, 129. S., AND LAW, V. G.

TeR Meulen, V., AND Love, R. . . 1967. J. Virol., 1, 626. 